provided data that allowed medical staff to reach agreement quickly with hospital management on measures that might solve the longstanding problem of house officer staffing in our medical wards. It seems unlikely that this measure of agreement would have been attained so easily had the information from the study not been available.

Secondly, the findings have wider relevance, providing an account of the patterns of work of a group of preregistration house officers in a large teaching hospital. Although the findings cannot be directly extrapolated to other hospitals, they show that accurate knowledge of the volume and type of workload are necessary to resolve problems of medical staffing in the 1990s. Attempts to reduce junior doctors' hours of duty by introducing or increasing cross cover arrangements are feasible only if this does not result in an excessive workload. Consequently, quantifying workload is as important as calculating hours on duty when changes in rota arrangements are being considered.

Posts for preregistration house officers are intended to provide not only a clinical service for patients but also supervised training and experience for the doctors. Many of the clerical activities of preregistration house officers contribute little to their training, and in our view employing filing clerks is worth while.

Medical workload cannot be appraised solely on the basis of time. The adequacy of communication with patients, particularly in respect of informing, reassuring, and comforting them, is important not only to the patients themselves but also for doctors' job satisfaction. This aspect of clinical activity is not easily measured, but its importance must be appreciated when the results of studies of work are interpreted.

This study was designed and undertaken to help resolve a specific problem in our hospital; it was not conceived as an investigation to generate results with a broader relevance. Consequently, although we are satisfied that it met the local need, the protocol may not be wholly appropriate for similar studies elsewhere. Likewise, the appropriate solution of house officers' problems may vary according to local circumstances. Issues such as the quality of training for preregistration house officers and the need to balance the number of preregistration posts available locally and nationally with the annual number of medical graduates are obviously relevant. Nevertheless, similar studies are necessary if the working patterns and training of junior doctors are to be improved without decreasing the quality of care.

We acknowledge the contributions and commitment of many medical staff, managers at the Royal Infirmary, Lothian Health Board, and representatives of the BMA to the design and execution of the study. The opinions expressed in this paper are ours.

1 United Kingdom Health Departments, Joint Consultants Committee, and Chairmen of Regional Health Authorities. Hospital medical staffing: achievin a balance. London: DHSS, 1987.

2 Scotland A. The hours doctors work. Brf Hosp Med 1989;41:211-2.

3 Lurie N, Rank B, Parenti C, Wooley T, Snoke W. How do house officers spend their nights? A time study of internal medicine house staff on call. NEngl f Med 1989;320:1673-7.

4 Payson HE, Gaenslen EC, Stargardter FL. Time study of an internship in university medical service. $N$ Engl f Med 1961;264:439-43.

(Accepted 9 March 1990)

\title{
Screening for carcinoma of the prostate by digital rectal examination in a randomly selected population
}

\author{
Knud V Pedersen, Per Carlsson, Eberhard Varenhorst, Owe Löfman, Kenneth Berglund
}

Department of Urology, University Hospital, 58185 Linköping, Sweden Knud V Pedersen, MD, urological registrar

Centre for Medical Technology Assessment and Department of Social and Environmental Medicine, Linköping University, Linköping, Sweden

Per Carlsson, PHD, assistant director

Owe Löfman, MD, head of department

Kenneth Berglund, MS, assistant director

Department of Urology, County Hospital,

Norrköping, Sweden

Eberhard Varenhorst, MD, associate professor

Correspondence to:

Dr Pedersen.

BrMed f 1990;300:1041-4

\section{Abstract}

Objective-To study the acceptability, costs, psychosocial consequences, and organisation of screening for carcinoma of the prostate.

Design-A randomly selected population was personally invited for digital rectal examination by a urologist and a general practitioner. Further examinations were performed if induration was felt. Each man completed a questionnaire on his response to the examination.

Setting-General practices in the area of Norrköping.

Patients-1494 Men aged 50-69 randomly selected from a population of 9026 .

Main outcome measure-Prostates having a firm nodular consistency.

Results-Carcinoma of the prostate was suspected in 45 of 1163 patients examined; in 10 by the general practitioners, in $\mathbf{1 0}$ by the urologists, and in 25 by both. Forty four men had a fine needle aspiration biopsy, and carcinomas were found in $\mathbf{1 3}$ cases. Of these, one had been suspected by the general practitioner, four by urologists, and eight by both. The cost for each man was $£ 11.60$, and the cost for each case of carcinoma detected and treated by potentially curative methods was $£ 2477$. Of the 13 men with carcinoma, 10 underwent radical prostatectomy and one radiotherapy. One man had. advanced disease and was given endocrine treatment, another was not treated. Only 193 men felt distress during the initial examination. Of the 44 men who had an aspiration biopsy, 25 experienced anxiety.

Conclusions-Screening for carcinoma of the prostate by a urologist or a general practitioner using digital rectal examination is a cost effective method of early diagnosis. Whether such screening leads to prolonged survival, however, remains doubtful.

\section{Introduction}

Cancer of the prostate is an increasing health problem in many countries. In Sweden it accounts for $23 \%$ of all cancers among men and is thus the chief form of cancer and the commonest cause of death from cancer in men. ${ }^{12}$ It often presents at an advanced stage with extensive local invasion or metastases, ${ }^{3}$ although it can be cured if detected early while still confined to the prostate; at this stage it usually causes no symptoms. Attention must therefore be focused on early detection and treatment. An effective screening programme that detected potentially curable prostatic cancer could alter the natural course of the disease by reducing overall mortality. Some major evaluations of screening programmes have been reported, but none of the populations was randomly selected ${ }^{4-7}$ and the reports did not give information about the prevalence and stage of prostatic cancer in an unselected population. Similarly, recent studies assessing digital rectal examination and transrectal ultrasonography were done in men who sought advice on their own initiative, who may therefore have constituted a biased, preselected 
population. ${ }^{+8}$ The acceptability of the examination technique, adverse effects such as psychological trauma when cancer was detected, and the inconvenience of the examination have not been investigated.

Digital rectal examination is the only established non-invasive method of diagnosing prostatic cancer. It is simple and universally available, and any doctor can perform it, although its results have been suggested to be subjective and difficult to record accurately. Interobserver variation and whether the examination should be done by a urological specialist or a general practitioner have not been assessed.

The Swedish system of personal identification numbers and the population based national cancer register facilitates selection of a screening population and control groups and long term observation. We evaluated the effectiveness, costs, acceptability, and psychological consequences of a decentralised screening programme in a randomly selected population. In addition, we obtained information about the prevalence and the stage of prostatic cancer detected by digital rectal examination in a high risk population.

\section{Subjects and methods}

We randomly selected 1494 men from the population at risk-namely, 9026 men aged 50-69, the total male population of that age in the area. We issued information twice to the public through the local television station and articles in national and local daily newspapers. An invitation was sent to the men selected.

Digital rectal examinations were performed at primary health care centres. The bladder was voided before rectal palpation, which was performed with the man standing and supported on the forearms with the knees flexed; he was asked to strain down to facilitate palpation of the upper parts of the prostate and the seminal vesicles. A senior urologist and a general practitioner performed the examination independently, and all findings were recorded immediately. The first examination was made by a urologist in 601 cases and by a general practitioner in 562 cases. A firm nodular consistency was the main criterion for malignancv. Prostates with a consistency close to normalfor example, slight induration-were classified as benign and were not examined further. If one or both of the examiners suspected malignancy the patient was informed immediately and a fine needle aspiration biopsy (three aspirates from each lobe) was performed one week later by an experienced cytologist. The patient was told the cytological diagnosis after another week, by the urologist personally if it was positive and by letter if it was negative.

\section{COST ANALYSIS AND ASSESSMENT OF DISTRESS}

Immediately after the examination we asked each man about discomfort during the examination and the amount of time the examination had taken up. After fine needle aspiration biopsy patients completed questionnaires about mental stress during the week before the procedure, physical discomfort, and the information they had been given. They completed another questionnaire on mental stress after they obtained the results of the biopsy.

Direct costs were calculated from the internal accounts of the health district administration and an estimate of travelling expenses.

\section{Results}

ORGANISATIONAL AND MEDICAL ASPECTS

We examined 1163 men ( $78 \%$ of those selected), the highest acceptance rate being in those aged 60-64 (table I). Among the 331 men who declined to attend 142
TABLE I-Number of men selected for, and uptake of, screening for cancer of prostate by age

\begin{tabular}{cccc}
\hline $\begin{array}{c}\text { Age } \\
\text { (years) }\end{array}$ & $\begin{array}{c}\text { No of men } \\
\text { at risk }\end{array}$ & $\begin{array}{c}\text { No randomly } \\
\text { selected }\end{array}$ & $\begin{array}{c}\text { No }(\%) \\
\text { examined }\end{array}$ \\
\hline $50-54$ & 2147 & 357 & $262(73)$ \\
$55-59$ & 2169 & 360 & $275(76)$ \\
$60-64$ & 2397 & 393 & $320(81)$ \\
$65-69$ & 2313 & 384 & $306(80)$ \\
\hline Total & 9026 & 1494 & $1163(78)$ \\
\hline
\end{tabular}

were anxious or were sceptical about the programme or the health service in general and 189 gave other reasons, including already being under medical treatment and having had a rectal palpation recently. Malignancy was suspected in 45 men (4\%), and all.but one of them had a fine needle aspiration biopsy. Thirteen cases of carcinoma were confirmed. The prevalence of cancer increased with increasing age, with the highest figure $(3 \%)$ in the oldest group. The overall prevalence was $1 \%$ (table II).

TABLE II -Number (percentage) of men suspected and confirmed to have cancer of prostate by age

\begin{tabular}{ccc}
\hline Age (years) & Suspected cancer & Confirmed cancer \\
\hline $50-54(\mathrm{n}=262)$ & $4(2)$ & \\
$55-59(\mathrm{n}=275)$ & $6(2)$ & $2(1)$ \\
$60-64(\mathrm{n}=320)$ & $15(5)$ & $2(1)$ \\
$65-69(\mathrm{n}=306)$ & $20(7)$ & $9(3)$ \\
\hline Total $(\mathrm{n}=1163)$ & $45(4)$ & $13(1)$ \\
\hline
\end{tabular}

We classified patients according to the classification of the International Union Against Cancer': one patient had T1 disease, $11 \mathrm{~T} 2$, and one T3. Malignancy was classed as G1 in seven patients and as G2 in six. One patient had distant metastases, and two had cellular atypia, which aspiration biopsies three months later found to be benign. Slight induration, judged to be benign, was noted in $192(16.5 \%)$ of cases.

The two doctors agreed on the diagnosis in 1143 $(98 \cdot 3 \%$ ) cases (suspicion of malignancy or no such suspicion). The general practitioners and urologists as groups each suspected malignancy in 34 cases (table III); the expected number of men with suspected carcinomas would therefore be $34 \times 34 / 1163=0.99$ and the expected number of men with normal prostates $1129 \times 1129 / 1163=1096$. Thus the agreement rate by

TABLE III - Predictive accuracy of digital rectal examination performed by general practitioners and urologists

\begin{tabular}{lccc}
\hline & & \multicolumn{2}{c}{$\begin{array}{c}\text { Result of fine needle } \\
\text { aspiration biopsy }\end{array}$} \\
\cline { 3 - 5 } & $\begin{array}{c}\text { No of } \\
\text { men }\end{array}$ & Positive & Negative \\
\hline Cancer suspected by: & & & \\
General practitioner and urologist & 24 & 8 & 16 \\
General practitioner alone & 10 & 1 & 9 \\
Urologist alone & 10 & 4 & 6 \\
\hline Total & $44^{\star}$ & 13 & 32 \\
\hline
\end{tabular}

*One man refused further examination.

chance would be $(0 \cdot 99+1096) / 1163$ or $94 \cdot 3 \%$. The ideal agreement rate is $100 \%$. A realistic measure of comparability is given by the statistic coefficient $x$, which is the proportion of the observed and the ideal agreement rates not accounted for chance and varies from -1 (complete disagreement) through 0 (agreement by chance) to +1 (complete agreement).${ }^{10}$ In our study $x$ was $(98 \cdot 3-94 \cdot 3) /(100-94 \cdot 3)=0.7$ for the whole population screened. In the smaller population of 44 subjects who were examined further $x$ was $(88 \cdot 6-63 \cdot 4) /(100-63 \cdot 4)=0 \cdot 69$.

The overall positive predictive value of the test was $0.30(13 / 44)(0.27$ for general practitioners and 0.35 
for urologists). The sensitivity and specificity of the method could not be calculated because the true prevalence of the disease is unknown.

The 13 patients found to have carcinoma were offered further examination and treatment: one patient had advanced disease and was given hormone treatment; another had concurrent disease and was not treated; and 10 were treated by radical prostatectomy and one by radiotherapy.

\section{ECONOMIC ASPECTS}

Ten men were examined per hour. The direct cost including salaries, materials, and rent was estimated at $£ 13536$, or $£ 11.60$ per examination, and the additional cost of the fine needle aspiration biopsy was $£ 3312$, or $£ 75.20$ per examination. The total direct cost, including travelling expenses, was thus $£ 21179 ; £ 1630$ per detected cancer or $£ 1925$ per subject treated by a potentially curative method.

Indirect costs, representing the participating men's loss of working and leisure time, were calculated as the average earnings including social costs for those examined during working hours (500 men); the costs for those examined outside working hours or who were retired were calculated from figures obtained from the British Ministry of Transport ${ }^{11}$ and were $£ 6003$, or $£ 5.20$ per man examined, including the cost of fine needle biopsy. The total cost of the screening programme was $£ 27209$, or $£ 2477$ for every cancer that could potentially be cured.

PSYCHOLOGICAL ASPECTS

Table IV shows the distress caused by the first examination. Younger men complained of more dis-

TABLE IV-Response of men when questioned about distress during digital rectal examination. Values are numbers (percentges)

\begin{tabular}{ccccc}
\hline & & \multicolumn{3}{c}{ Degree of distress } \\
\cline { 3 - 5 } $\begin{array}{c}\text { Age } \\
\text { (years) }\end{array}$ & $\begin{array}{c}\text { No } \\
\text { examined }\end{array}$ & Major & Minor & None \\
\hline $50-54$ & 262 & $10(4)$ & $39(15)$ & $213(81)$ \\
$55-59$ & 274 & $13(5)$ & $49(18)$ & $212(77)$ \\
$60-64$ & 317 & $12(4)$ & $43(13)$ & $262(82)$ \\
$65-69$ & 306 & $2(1)$ & $26(8)$ & $278(91)$ \\
\hline Total & 1163 & $38(3)$ & $157(13)$ & $965(83)$ \\
\hline
\end{tabular}

tress than older ones, but most did not experience any distress. Of the 44 men who were recalled on suspicion of malignancy, 25 were anxious during the week of waiting, four had nightmares, and 18 were more nervous than normal. Thirty one felt anxious while awaiting the cytologist's report and most were more nervous than normal.

\section{Discussion}

Early diagnosis of prostatic carcinoma is a prerequisite for a cure. Unfortunately, symptoms develop late and self examination is not possible. Screening programmes have been suggested but have not been evaluated in controlled trials. We randomly selected men aged 50-69 for screening. Prolonged survival of men aged over 70 given curative treatment for prostatic cancer would not be expected. ${ }^{12}$

Almost $80 \%$ of the men invited agreed to participate; this was a high acceptance rate that is comparable with the uptake of mammographic screening for breast cancer in Sweden. ${ }^{13}$ Digital rectal palpation was readily tolerated, with less than $10 \%$ of the men expressing negative attitudes to the screening. The method is noninvasive, cheap, and fast, and any doctor can learn to perform it.

The diagnoses of the general practitioners and urologists sometimes disagreed. A high proportion of normal subjects will give a high agreement rate, ${ }^{10}$ but greater care and greater experience will produce closer agreement. ${ }^{10}$ The technique had a higher positive predictive value when done by the urologists than the general practitioners, who had less experience of it. In similar age groups Lee et al found 30\% more suspected cancers by ultrasonic than by digital examination, but the positive predictive value of the two methods was equal. ${ }^{4}$

The expected incidence of prostatic cancer, derived from the national cancer register, would be $0 \cdot 15 \%$ a year, compared with the $1 \%$ we detected. ${ }^{1}$ This figure is seven times the clinical incidence in Sweden for the same age groups.

Transrectal fine needle aspiration biopsy has become routine for diagnosing prostatic cancer in Sweden over the past 30 years. Its overall accuracy is about $94 \%$, and it has won general recognition as a fast and safe procedure in many other countries. ${ }^{14}$

The most important goal is of course to detect curable cancers and to provide treatment for them. Necropsy studies have disclosed small prostatic cancers in $30-50 \%$ of men aged over $50^{15}$; few would have progressed to a lifethreatening state. Oversensitive methods will disclose too many tumours that do not require treatment. No single tumour marker exists that can determine whether potentially curative treatment should be given, with the possible exception of age. ${ }^{12}$ We treated 11 of 13 patients with potentially curative methods. The cost of screening per treated patient is less than that with other screening procedures for malignancy - for example, mammography for breast cancer. ${ }^{13}$ We have shown that a programme for early detection of prostatic carcinoma can be organised as an integrated part of the routine work of the health service. We are convinced that with further education and increased assiduity on the part of the general practitioners the positive predictive value of digital rectal palpation will increase to that attained by urologists. Screening could of course be done in connection with attendance for other reasons. If large populations are to be examined major demands will be made on the health system, and screening will affect staffing and equipment of the urology, oncology, and cytology departments. There is no evidence from randomised studies that early detection of prostatic carcinoma and potentially curative treatment can prolong survival; the only prospective study with a placebo control group could reach no definite conclusions. ${ }^{16}$ We have indicated how a screening procedure could be designed, but the appropriateness of such programmes must be evaluated.

This study was supported by the Swedish Cancer Foundation.

1 Cancer Registry of National Board of Health and Welfare. Cancer incidence in Sweden 1985. Stockholm: Liber Förlag, 1987.

2 National Bureau of Statistics. Causes of death 1986. Stockholm: Nationa Bureau of Statistics, 1988.

3 Varenhorst E, Ålund G, Lindström E, Månson JC. Bone marrow aspiration biopsy and bone scanning in the staging of prostatic cancer. $\mathrm{Br} \mathcal{F}$ Uro 1983;5:534-7.

4 Lee F, Littrup PJ, Torp-Pedersen ST, et al. Prostate cancer: comparison of transrectal US and digital rectal examination for screening. Radiolog 1988;168:389-94.

5 Chodak GW, Schoenberg HW. Early detection of prostate cancer by routine screening. IAMA 1984;252:3261-4.

6 Vihko $P$, Kontturi $M$, Lukkarinen $O$, Ervasti J, Vihko R. Screening for carcinoma of the prostate. Cancer 1985;56:173-7.

7 Faul P. Experience with the German annual preventive checkup examination. In: Jacobi GH, Hohenfellner R, eds. Prostate cancer. Baltimore: Williams and Wilkins, 1982;57-70.

8 Vallancien G, Prapotnich D, Sibert L. Comparison of the efficacy of digital rectal examination and transrectal ultrasonography in the diagnosis of prostatic cancer. Eur Urol 1989;16:321-4.

9 International Union Against Cancer. Urological tumours. In: Hermanek P, Sorbin LH, eds. TMN classification of malignant tumours. 4 th ed. Berlin Springer Verlag, 1987:121-6.

10 Koran LM. The reliability of clinical methods, data and judgments. N Engl f Med 1975;293:695-701. 
11 McGuire A, Henderson J, Mooney G. Cost benefit approach in theory. In The economics of health care. London: Routledge and Kegan Paul, 1988: 74-101

12 Goodman CM, Busuttil A, Chisholm GD. Age and size and grade of tumour predict prognosis in incidentally diagnosed carcinoma of the prostate Br F Urol 1988;62:576-80.

13 Hăkansson $\mathrm{S}$, Jonsson E. Screening for cancer-underlaget dåligt för kalkyl om kostnader och nytta. Lakartidningen 1984;81:4734-42.

14 Esposti P-L. Aspiration biopsy and cytological evaluation for primary diagnosis and follow-up. In: Jacobi GH, Hohenfellner R, eds, Prostute cancer. Baltimore: Williams and Wilkins, 1982:71-93.

15 Lundberg S, Berge T. Prostatic carcinoma. An autopsy study. Scand f Urol

16 Madsen PO, Graversen PH, Gasser TC, et al. Treatment of localised prostatic cancer. Radical prostatectomy versus placebo. A 15 year follow-up. Scand 7 Urol Nephrol 1988;suppl 110:95-100.

\title{
Is intrauterine growth retardation with normal umbilical artery blood flow a benign condition?
}

\author{
Gerard Burke, Bernard Stuart, Patricia Crowley, Siobhán Ní Scanaill, John Drumm
}

\begin{abstract}
Objective-To determine whether intrauterine growth retardation associated with normal umbilical artery blood flow is a benign condition.

Design-A prospective comparative study of growth retarded fetuses with normal and abnormal umbilical artery blood flow.

Setting-The fetal assessment clinic of a large maternity hospital in Ireland.

Patients - 179 Women with singleton pregnancies in which the fetal abdominal circumference, measured by ultrasonography, was below the fifth centile for gestation.

Main outcome measures-Perinatal deaths, fetal distress requiring caesarean section, preterm delivery, cerebral irritation.

Results-Of 124 fetuses with normal flow, all physically normal fetuses survived but one baby had cerebral irritation; there were six preterm deliveries and four caesarean sections for fetal distress. Among 55 women with physically normal fetuses with abnormal flow there were two midtrimester abortions, three perinatal deaths, and one case of cerebral irritation; there were 23 preterm deliveries and six caesarean sections for fetal distress in labour.

Conclusions-Intrauterine growth retardation associated with normal umbilical blood flow is a different entity from that associated with abnormal flow, normal flow being largely benign and abnormal flow carrying a serious risk of adverse outcome.
\end{abstract}

\section{Introduction}

Intrauterine growth retardation is an important cause of perinatal death. In the Republic of Ireland the death rate in late pregnancy of normal fetuses weighing between 2000 and $2499 \mathrm{~g}$ was $37 \cdot 2$ and $39 \cdot 7$ per 1000 in 1986 and 1987 respectively. ${ }^{1}$ Babies of this birth weight accounted for only $2 \cdot 7 \%$ of total births but for $27 \cdot 6 \%$ of the deaths of normal fetuses in late pregnancy. No reliable method exists to establish whether a fetus is small because of placental insufficiency or because of genetic and racial factors, when it is small but appro-

Coombe Lying-In Hospital, Dublin 8, Ireland

Gerard Burke, MRCOG, research registrar

Bernard Stuart, FRCOG, consultant

Patricia Crowley, MrCoG, senior lecturer

Siobhán Ní Scanaill, RM, ultrasonographer

John Drumm, FRCOG, master

Correspondence to:

Dr Burke. growth retarded. Consequently, women with small but healthy fetuses may be admitted to hospital unnecessarily and have unneeded intervention, including caesarean section.

Intrauterine growth retardation associated with normal umbilical artery blood flow has been suggested to be a largely benign condition. ${ }^{2}$ A recent report suggested that Doppler studies of the umbilical artery can identify a group of growth retarded babies at increased risk of intrapartum hypoxia. ${ }^{3}$ Cordocentesis has shown a significant negative correlation between the severity of fetal hypoxia and the mean velocity of blood in the fetal aorta. ${ }^{+}$In addition, although no correlation has been found between the size of the fetus and hypoxia or acidosis, absence of end diastolic blood flow seemed to be a good marker of asphyxia in growth retarded fetuses.

We tested the hypothesis that intrauterine growth retardation associated with normal patterns of umbilical artery blood flow is largely benign.

\section{Patients and methods}

All high risk patients referred to the fetal assessment clinic at this hospital from September 1988 to May 1989 were entered into the study. Each woman had fetal biometry, and the biophysical profile of the fetus was scored. ${ }^{6}$ Suspected intrauterine growth retardation was the commonest indication for referral to the clinic. Growth retardation was diagnosed if the fetal abdominal circumference, measured by ultrasonography, was below the fifth centile for gestation. ${ }^{7}$ All women underwent velocity waveform analysis of the umbilical artery by continuous wave Doppler ultrasound at each visit to the clinic. The equipment consisted of a real time ultrasound scanner (General Electric RT 3600) and a spectrum analyser (Doptek 9012) which has a high pass filter of $150 \mathrm{~Hz}$. Informed consent was obtained from each patient, and ethical approval was granted by the hospital.

Results of the Doppler investigation were withheld from the doctors managing the cases. We calculated the peak systolic to end diastolic ratio for each fetus and identified three blood flow patterns: in type 1 the ratio was $\leqslant 2$ SD above the mean for gestational age ${ }^{8}$; in type 2 the ratio was $>2$ SD above the mean; and in type 3 end diastolic blood flow was absent or reversed.

Birthweight centiles for gestation were based on standards for Irish neonates ${ }^{9}$ and were not applied to babies born before 34 weeks' gestation as no reliable data were available. A perinatal death was defined as a stillborn fetus weighing $\geqslant 500 \mathrm{~g}$ or the death within seven days of birth of a neonate who weighed $\geqslant 500 \mathrm{~g}$ at birth. Cerebral irritation was defined as convulsions, abnormal reflexes, or abnormal tone in the first seven days after birth. ${ }^{10}$

We calculated relative risks and $95 \%$ confidence intervals according to the method of Morris and Gardner. ${ }^{11} \chi^{2}$ Tests, with correction for continuity, were performed for discrete variables.

\section{Results}

At the final assessment 179 fetuses had an abdominal circumference below the fifth centile. Of these, 124 had normal umbilical artery velocity waveforms. Forty four fetuses had type 2 flow and 11 had type 3 . Table I shows the outcome of pregnancy according to the type of umbilical artery blood flow. In the group with type 3 flow there were two midtrimester abortions: one fetus was born alive but weighed less than $500 \mathrm{~g}$ and could not be resuscitated. Of the 166 babies born after 34 